\title{
A EDUCAÇÃO AMBIENTAL PARA A GESTÃO DOS RESÍDUOS DA CONSTRUÇÃO CIVIL NO MUNICÍPIO DO RIO GRANDE (RS)
}

\author{
Daniele Kalil Juliano ${ }^{1}$ \\ Vanessa Hernandez Caporlingua ${ }^{2}$
}

Resumo: O presente artigo tem por objetivos investigar sobre a destinação e regulamentação dos resíduos da construção civil, compreender as consequências socioambientais de sua produção e destinação e investigar a potencialidade da Educação Ambiental na redução dos problemas socioambientais delas advindos. A abordagem metodológica qualitativa foi o estudo de caso, com análise do material pela Análise Textual Discursiva. Os resultados indicaram fragilidades estruturais, falta de ações de Educação Ambiental Crítica, contaminação ambiental e a necessidade de maior atuação da administração pública, na implementação de medidas práticas e em atividades de Educação Ambiental, enquanto política pública, com maior atenção para a participação social.

Palavras-chave: Educação Ambiental; Participação Social; Resíduos da Construção Civil.

${ }_{1}^{1}$ Universidade Federal do Rio Grande - FURG. E-mail: danielejuliano1@gmail.com

2 Universidade Federal do Rio Grande - FURG. E-mail: vanessac@vetorial.net

Revbea, São Paulo, V. 12, № 2: 209-228, 2017.

revista brasileira educação ambiental 


\section{Introdução}

O presente artigo foi realizado tendo por base a dissertação intitulada "A Educação Ambiental para os Resíduos da Construção Civil no Município do Rio Grande/RS" e tem como propósito compreender como a Educação Ambiental (EA) poderá auxiliar na política de redução da produção e da adequada destinação dos resíduos da construção civil (RCC) no Município do Rio Grande - RS.

Segundo Loureiro (2006), a organização da sociedade atual é baseada na aceleração de produção de riquezas, sendo uma sociedade de consumidores, de desperdício. Entendemos que, nesta organização social, a concretização de sonhos de consumo pode trazer satisfação momentânea com efeitos negativos duradouros ao meio ambiente. Neste cenário, conforme Karpinsk (2009), tem destaque a indústria de construção civil, como principal geradora de resíduos sólidos - até $60 \%$ do total gerado no Brasil, grande parte passível de reutilização ou reciclagem. Estes resíduos comumente são eliminados de forma irregular em terrenos baldios, encostas de rios, ruas e praças ocasionando problemas ambientais e sociais como: poluição das águas, assoreamento dos rios, enchentes e doenças como leptospirose e dengue provenientes de insetos e animais que ocupam os entulhos, atraindo ainda o lançamento de outros tipos de resíduos não inertes, de modo a acelerar a degradação ambiental (KARPINSK, 2009).

Segundo o Plano Municipal de Saneamento Básico do Município do Rio Grande - PMSB (PREFEITURA MUNICIPAL DO RIO GRANDE, 2013), município alvo do estudo de caso realizado na presente pesquisa, na cidade atualmente o único local para dispor os RCC é um bota-fora sem licença ambiental, e não há uma política de motivação e sensibilização para minimizar sua produção e maximizar sua reciclagem/reutilização. Ainda, apenas cerca de $20 \%$ dos RCC são destinados ao local, sendo aproximadamente $80 \%$ dispostos incorretamente. O desperdício é significativo e representativo no custo de execução de grandes obras (MMA, 2014).

Notadamente, vislumbramos a necessidade de adequação técnica e de transformação consciente das relações socioambientais para prevenção de problemas futuros. Para transformação do cenário apontado, tanto local como global, merece destaque a EA Crítica, pois ela ocorre através da promoção de ambientes educativos que estimulem reflexão e intervenção, sendo seu público "a sociedade constituída por seus atores individuais e coletivos, em todas as faixas etárias" (LAYRARGUES, 2004, p.33). Conforme Loureiro (2006), a EA Crítica possibilita a transformação das condições de vida pela atividade unitária entre o pensar e a ação alicerçada no conhecimento, bem como na capacidade de realizar opções compromissadas com o outro e com a vida, consideradas as relações entre educação, sociedade, trabalho e natureza de forma crítica e dialógica, em um processo permanente de aprendizagem. Entendemos que é a partir do conhecimento para reflexão e ação conscientes que se dá a transformação da sociedade, a superação do senso comum e a formação de uma postura crítica capaz de modificar as práticas sociais.

Revbea, São Paulo, V. 12, № 2: 209-228, 2017. 
Neste sentido, consideramos que as constatações advindas do estudo da adequação do Município do Rio Grande aos preceitos legais são importantes para apontar se há fragilidades ocasionadas pela falta ou equivocada regulamentação e destinação, a fim de que se possa verificar se a gestão municipal figura ou não como obstáculo à transformação almejada, uma vez que não seria suficiente propor a educação de forma ingênua, desconhecendo a realidade em que estamos inseridos.

Assim, os objetivos da pesquisa foram estruturados de forma a compreender as consequências socioambientais ${ }^{3}$ da inadequada destinação dos RCC; investigar a destinação mencionada e a sua regulamentação, bem como sua adequação aos preceitos legais; e investigar a potencialidade da EA na minimização da produção e na correta destinação dos RCC.

\section{Metodologia}

Fizemos a opção pela metodologia predominantemente qualitativa, bibliográfica e documental. $\mathrm{O}$ tipo de abordagem metodológica qualitativa escolhida foi o estudo de caso, devido à sua adequação para investigar problemas práticos. $O$ estudo de caso é divido em três fases, quais sejam: fase exploratória ou de definição de focos de estudo, fase da coleta dos dados ou de delimitação do estudo e fase de análise sistemática dos dados (ANDRÉ, 2008). A fase exploratória, ou de definição de focos de estudo, foi dividida em três momentos, de acordo com os objetivos propostos. No primeiro momento, investigou-se a destinação de RCC e a regulamentação da Prefeitura Municipal de Rio Grande-RS, bem como sua adequação aos preceitos legais, a partir de estudo bibliográfico e documental. Como técnica de tratamento dos dados obtidos, foi empregada a análise de conteúdo, sistematizando as informações em categorias estratégicas para sua compreensão (ANDRÉ, 2008). As constatações advindas deste estudo foram importantes para apontar se há fragilidades ocasionadas pela falta ou equivocada regulamentação e destinação dos RCC, a fim de que se pudesse observar se a gestão municipal figura ou não como obstáculo à transformação almejada.

No segundo momento, compreendeu-se as consequências socioambientais da inadequada destinação dos RCC a partir dos planos de resíduos sólidos. A partir desta compreensão, percebeu-se a amplitude e a importância do tema, vislumbrando-se a necessidade de adequação social para prevenção de problemas acentuados. Para tanto, o método aplicado foi conduzido através de estudo bibliográfico e documental, envolvendo a coleta de dados pertinentes ao cenário socioambiental nacional, estadual e principalmente do município, caracterizando o descarte dos RCC no município. A partir deste diagnóstico

\footnotetext{
3 Definimos por socioambientais as relações dos homens entre si e destes com o meio ambiente, com base no entendimento de Loureiro (2006), de que a dialética entre o social e o natural é necessária para a $\mathrm{EA}$, diante da complexidade da totalidade e da organização da vida, sendo o homem social por natureza e sendo ele parte do meio ambiente.
}

revista brasileira educação ambiental 
introduziu-se, com base em bibliografia, considerações sobre as consequências socioambientais advindas.

O estudo bibliográfico e documental realizado serviu como base para a compreensão e para o aprofundamento da investigação da potencialidade da EA na minimização da produção e na correta destinação dos RCC, que é nosso terceiro momento. Através deste estudo, pretendemos um espaço para o desenvolvimento da EA Crítica, através da qual o sujeito possa tomar decisões consciente e motivado para preservação socioambiental.

$\mathrm{Na}$ segunda fase, de coleta de dados, obtivemos informações sobre a separação e destinação de resíduos, bem como o reuso de material, investigando se há preocupação em preservar o meio ambiente através do correto manejo e destinação do resíduo. Foram realizadas também entrevistas com gestores da administração pública do município - prefeito, secretário do meio ambiente e secretário adjunto de controle e serviços urbanos ${ }^{4}$, para investigar quais ações de gestão e EA foram planejadas para os RCC.

Para a terceira fase, de análise sistemática dos dados e elaboração do relatório, utilizamos o método de análise textual discursiva - ATD, através da construção e desconstrução do discurso e emergência de categorias (MORAES; GALIAZZI, 2007), produzindo um entendimento mais profundo dos discursos analisados.

\section{Análise comparativa da política nacional e dos planos estadual e municipal de resíduos sólidos}

A fim de apurar fragilidades advindas da falta ou equivocada regulamentação e destinação dos RCC no Município do Rio Grande-RS, a serem observadas pela gestão municipal na preservação do meio ambiente, traçamos um comparativo da política municipal com as políticas nacional e estadual. Esta análise se deu a partir da sistematização das informações em categorias, abrangidas metas, princípios, objetivos e previsão da EA como instrumento de ação, com base no conteúdo do Plano Municipal de Saneamento Básico - PMSB, do Plano Estadual de Resíduos Sólidos - PERSRS (MMA, 2014) e da Política Nacional de Resíduos Sólidos - PNRS - Lei nº 12.305/2010 (BRASIL, 2010).

A importância desta análise e da consequente constatação da necessidade de adequações para benefício socioambiental encontra alicerce no art. 225 da Constituição Federal (BRASIL, 1988), segundo o qual todos têm direito ao meio ambiente equilibrado, essencial à sadia qualidade de vida, impondo-se ao Poder Público e à coletividade o dever de defendê-lo e preservá-lo. Ainda, consoante o $\S 1^{\circ}, \mathrm{VI}$, incumbe ao Poder Público promover a EA em todos os níveis de ensino e a conscientização pública para a sua preservação. Esse diploma legal consagra o direito fundamental ao meio

${ }^{4}$ Adiante identificados respectivamente por Prefeito, Secretário1 e Secretário2.

Revbea, São Paulo, V. 12, No 2: 209-228, 2017. 
ambiente, o qual conforme afirma Caporlingua (2012), é aglutinador entre o Direito e a EA, uma vez factível a reflexão de que, mesmo se traçados caminhos diferentes, deverão ao final conectar-se, pela compreensão da necessidade de promover a reconstrução do meio ambiente, através de atitudes concretas em benefício de uma sociedade melhor.

A partir desta compreensão, entendemos que a criação da PNRS foi importante avanço para o país no enfrentamento de problemas socioambientais advindos do inadequado manejo dos resíduos sólidos, constituindo importante referência, com a qual o PERS-RS em âmbito estadual e o PMSB na esfera municipal devem estar coadunados. Em virtude disso, bem como de que consideramos que a conexão, tanto da legislação municipal quanto da estadual, com a legislação nacional é particularmente importante, em razão de o meio ambiente ser de interesse difuso ${ }^{5}$, conforme expresso no art. 129, III, da Constituição Federal (BRASIL, 1998), ou seja, de todos os brasileiros, individual ou coletivamente, a seguir traremos a análise das metas, princípios, objetivos e EA como instrumento de ação, investigando sobre a adequação da regulamentação municipal a partir do PMSB à luz da PNRS e do PERS-RS.

Estão elencadas como metas, tanto na PNRS quanto no PERS-RS, previstas para redução da destinação inadequada dos resíduos: a eliminação das áreas de disposição irregular (bota-foras) até 2014; a implantação de aterros Classe A (área de reservação de material); a implantação de Ecopontos (pontos de entrega voluntária); a reutilização e reciclagem, com o fomento de cooperativas; a destinação dos RCC segundo sua classificação; a elaboração de planos de gerenciamento pelos grandes geradores e a elaboração de diagnóstico da geração, coleta e destinação dos resíduos. $\mathrm{Na}$ análise realizada no âmbito municipal, percebemos que as metas encontram correspondência no PMSB, com exceção da criação de aterro Classe A para a desativação do botafora irregular. Constatamos ainda que embora existentes como metas, a disponibilização de locais apropriados à reservação de RCC separados segundo sua classificação e o desenvolvimento de cooperativas são inexistentes, sendo o bota-fora uma área de contaminação ambiental que recebe outros resíduos sólidos; também não foram criados os Ecopontos para pequenos volumes - até $1 \mathrm{~m}^{3}$, a fim de desestimular sua deposição em terrenos e vias públicas (PREFEITURA MUNICIPAL DO RIO GRANDE, 2013). Esta falta de correspondência para a criação do aterro Classe $A$, bem como de implementação das metas referidas, constituem fragilidades municipais importantes para a gestão, que comprometem o manejo dos resíduos, conforme abordaremos adiante. Entendemos que tais inadequações figuram ainda em prejuízo da meta nacional, porquanto esta requer em sua consecução o encadeamento de cada um dos entes federativos.

\footnotetext{
5 O conceito de direitos difusos está na Lei no 8.078/90, art. 81, inciso I, entendidos como transindividuais, de natureza indivisível, de que sejam titulares pessoas indeterminadas e ligadas por circunstâncias de fato (BRASIL, 2007).
}

revista brasileira educação ambiental 
Quanto aos princípios que fundamentam a PNRS, estes também são contemplados no PERS-RS, dentre os quais destacamos: a prevenção e a precaução; a gestão com base na ecoeficiência e o consumo de recursos naturais; a cooperação entre o poder público, o setor empresarial e demais segmentos da sociedade; o reconhecimento do resíduo sólido reutilizável e reciclável como um bem econômico e de valor social, gerador de trabalho e renda e promotor de cidadania; o respeito às diversidades locais e regionais $\mathrm{e}$ o direito da sociedade à informação e ao controle social (BRASIL, 2010). No âmbito municipal, os princípios expressos no PMSB diferem em parte daqueles previstos na PNRS, sem entretanto colidir com eles, prevendo promoção do protagonismo social a partir da criação de canais de acesso à informação e à participação que possibilitem a conscientização e a autogestão da população; promoção da saúde pública; promoção da educação sanitária e ambiental que vise à construção da consciência individual e coletiva e de uma relação mais harmônica entre o homem e o ambiente; sustentabilidade; proteção ambiental e informação tecnológica. Contemplam os princípios dos documentos nacional e estadual, demonstrando, assim como estes, a preocupação com a participação coletiva e o protagonismo social para a gestão eficaz rumo à sustentabilidade.

Também os objetivos previstos na PNRS encontram equivalentes na legislação estadual, merecendo destaque: proteção da saúde pública e da qualidade ambiental; não geração, redução, reutilização, reciclagem e tratamento dos resíduos sólidos e disposição final ambientalmente adequada dos rejeitos; incentivo à indústria da reciclagem e ao desenvolvimento de sistemas de gestão ambiental e empresarial voltados para a melhoria dos processos produtivos e ao reaproveitamento dos resíduos sólidos (BRASIL, 2010). Quanto aos objetivos municipais, estes não fazem parte de um rol definido, estando dispersos no texto, sendo previstas no PMSB a busca de práticas eficientes e adequadas para a coleta e destinação final dos diversos tipos de resíduos gerados no município, com remediação de áreas contaminadas, protegendo o meio ambiente e a saúde da população, por meio do planejamento dentro de um processo participativo (PREFEITURA MUNICIPAL DO RIO GRANDE, 2013, p.3). Assim, de modo geral, coadunamse com os objetivos previstos nas esferas nacional e estadual, uma vez que visam à proteção socioambiental por meio de práticas corretas de coleta e de destinação do resíduo sólido, visando à qualidade ambiental.

No que concerne à EA, observamos que está expressa como um dos instrumentos de ação tanto na PNRS, como no PERS-RS, para o alcance de suas metas, estando associada às ideias de redução do consumo, da valorização do resíduo como recurso e da essencialidade da participação social para uma postura crítica e transformadora da realidade socioambiental. A EA consta também no PMSB como instrumento para o alcance de suas metas, conferido destaque para a necessidade de EA nos bairros, "como instrumento orientador dos procedimentos e informações importantes que permeiam a gestão dos resíduos tanto sob o ponto de vista dos serviços oferecidos pela municipalidade quanto das ações particulares de cada indivíduo" (PREFEITURA MUNICIPAL DO RIO GRANDE, 2013, p.42). Entretanto, Revbea, São Paulo, V. 12, № 2: 209-228, 2017. 
percebemos a partir do PMSB que a SMMA fornece informações e promove ações pontuais, que não promovem a compreensão e a reflexão. Em sua prática, buscam garantir que a população terá o mesmo procedimento frente às questões relacionadas com a gestão dos resíduos, limitando-se a explicações para seu correto manuseio e para a padronização do uso dos serviços oferecidos. Entendemos que é desperdiçada a oportunidade de promover a consciência social para a transformação social, havendo riscos de reforçar o discurso hegemônico de poder, segundo o qual o conhecimento é detido por parcela da população, devendo os demais adequarem-se ao que é ensinado. Diante disso, temos que as ações de EA não atingiram status de adequação, uma vez que prescindidas de análise crítica e reflexão e, portanto, de seu caráter emancipatório.

Da falta de ações de EA Crítica emancipatórias, bem como das fragilidades operacionais apuradas, observamos a necessidade de mais ação da administração pública, tanto na implementação de medidas práticas quanto na realização de atividades efetivas de EA, entendimento que é reforçado a partir do estudo do diagnóstico a seguir.

\section{Educação Ambiental Crítica para o Manejo dos Resíduos da Construção Civil}

Traremos a seguir, a partir de estudo bibliográfico e documental, o diagnóstico nacional, estadual e principalmente municipal do manejo dos RCC, com considerações sobre sua inadequação $e$ as consequências socioambientais dela advindas. Desse modo é possível perceber a amplitude e relevância do tema, assim como a necessidade de adequação da gestão, para além da regulamentação trazida anteriormente, por meio da EA Crítica para a atuação em defesa do meio ambiente saudável, com prevenção de problemas acentuados.

Neste sentido, o diagnóstico auxilia na compreensão das consequências socioambientais da incorreta destinação dos RCC no município e apresenta dados fundamentais na gestão dos RCC com vistas à sustentabilidade ${ }^{6}$, com um conjunto de informações importantes para propostas de metas e de ações eficientes e eficazes na promoção de políticas públicas de caráter preventivo.

A importância do tema é marcada inicialmente pelo grande volume de RCC gerado. Segundo o Manual de áreas de manejo de resíduos da construção e resíduos volumosos (BRASIL, 2005), os RCC são de baixa

\footnotetext{
${ }^{6} \mathrm{O}$ conceito de sustentabilidade pressupõe o conhecimento e respeito dos ciclos materiais e energéticos de seus ecossistemas; o atendimento das necessidades humanas sem comprometer o contexto ecológico e com respeito às demais espécies; a garantia da existência de atributos essenciais ao funcionamento dos ecossistemas; o reconhecimento de quais são seus fatores limitantes, preservando-os para conservar sua capacidade de reprodução; e o planejamento de atividades humanas a partir de projeções futuras, com base nos saberes disponíveis. Devem ser consideradas necessidades econômicas e culturais interdependentes, como a subsistência, a proteção, o afeto, a criação, a produção, a reprodução biológica, a participação na vida social, a identidade e a liberdade (LOUREIRO, 2012).
}

revista brasileira educação ambiental 
periculosidade de contaminação, mas de grande impacto porquanto representam entre 50 e $70 \%$ do total dos resíduos sólidos urbanos, representado na figura abaixo conforme dados de 2015, referentes ao montante registrado junto aos municípios (Figura 1).

\section{Região 2014 2015 RCD Coletado (t/dia) / Índice (Kg/hab/dia) $\quad$ RCD Coletado (t/dia) / Índice (Kg/hab/dia) \\ BRASIL $122.262 / 0,603$ 123.721/0,605}

Figura 1: Quantidade total de RCC coletado pelos municípios no Brasil Fonte: ABRELPE (2015), p. 64.

Esta comparação entre os dados de 2015 e 2014, com base Panorama dos resíduos sólidos no Brasil (ABRELPE, 2015), resulta na constatação de um aumento de $1,2 \%$ na quantidade coletada, o que nos demonstra a importância da mudança de comportamento e de efetivas práticas de gestão, incluída a EA para a população, a fim de modificar este cenário de contínua progressão no consumo de recursos naturais e produção de resíduos.

Segundo o PERS-RS, a construção civil esteve em contínua expansão no RS, sendo a média de geração de RCC, calculada com base no ano de 2011, equivalente a $520 \mathrm{~kg} / \mathrm{hab}$ por ano, previsto ainda um crescimento contínuo embora não linear da produção de RCC. Quanto ao Município do Rio Grande, de acordo com o PMSB a previsão média por habitante para o ano de 2015 foi de $500 \mathrm{~kg} / \mathrm{hab}$ por ano, cálculo feito com base nos dados de 101.371 toneladas para 202.743 habitantes, quantidades expressivas que demonstram a relevância da correta gestão dos RCC. Ainda, o PMSB aponta para um crescimento da população e das demandas por saneamento básico, com um adensamento demográfico de 1068 habitantes ao ano, o que igualmente nos leva a concluir pela necessidade de promoção da EA Crítica para a população em geral, a fim de, conforme Loureiro (2006), proporcionar a reflexão acerca do modo como vivemos e da transformação dos valores e práticas sociais contrários ao bem-estar público, colocando a sustentabilidade acima de ideais desenvolvimentistas.

Outro aspecto importante, segundo o PMSB, é o de que, devido à inexistência de aterro especial, o entulho é destinado ao bota-fora irregular, ou simplesmente aterrado em áreas sem a permissão do poder público, ou ainda descartado às margens de cursos d'água, vias públicas, praças, parques, entre outros, o que configura crime ambiental, consoante previsto nos arts. 47, II, da PNRS - 12.305/2010 e art. 54, §2º, V, da 9.605/1998. Ademais, apenas $20 \%$ do total gerado de RCC é levado até o bota-fora, enquanto o restante tem destinação indeterminada, com aumento de áreas degradadas, incentivando ainda a deposição de outros resíduos sólidos, com contaminação ambiental e desenvolvimento de problemas ambientais como enchentes e doenças provenientes de insetos e animais que se proliferam. A partir da realização de audiências públicas, foram obtidos dados de participantes agrupados por bairro Revbea, São Paulo, V. 12, № 2: 209-228, 2017. 
(PREFEITURA MUNICIPAL DO RIO GRANDE, 2013), sendo que do total de 59 bairros, 44 relataram apresentar o problema de descarte inapropriado de RCC, retratando a irregularidade na deposição dos resíduos e a necessidade de adoção de medidas efetivas de gestão, como o cadastramento e fiscalização das empresas de coleta de RCC. Esta falta de controle acaba incentivando o descarte inadequado e dificultando a correta quantificação de RCC, dados importantes para a gestão, como no caso da implantação de uma usina de beneficiamento dos RCC e de cooperativas para sua classificação.

Se por um lado a disposição de RCC nas vias resulta na necessidade de ações de limpeza de caráter emergencial, com resultados aquém do necessário e com custo para os cofres públicos de $R \$ 25,00 / \mathrm{m}^{3}$ - chegando a $\mathrm{R} \$ 40,00 / \mathrm{m}^{3}$ com transporte, por outro lado o valor de venda do agregado reciclado é de $R \$ 30,00 / \mathrm{m}^{3}$, com um mercado potencial estadual de venda inicial de $R \$ 125.753 .149$ em 2015, podendo chegar a $R \$ 257.882 .024 \mathrm{em}$ 2034 (MMA, 2014). Diante disso, nos parece que a valorização do RCC, além de rentável, é uma medida eficaz para o meio ambiente, de modo que uma correta gestão dos RCC, que conte com o seu beneficiamento, resulta na produção de agregados com empregabilidades diversas e na diminuição de uso de recursos minerais no setor.

A respeito das ações de EA, a PNRS, o PERS-RS e o PMSB referem que sua realização tem se dado nos ambientes escolares, em detrimento de ações voltadas à população e aos agentes diretamente envolvidos com 0 manejo dos RCC. Desse modo, resta prejudicada a intenção expressa nestes documentos, de utilização da EA como instrumento de organização e democratização das informações, com o desenvolvimento de mecanismos de divulgação e participação social, para mobilização do interesse e da participação dos profissionais da área e da população como um todo. A perspectiva de EA constante destes documentos manifesta-se como crítica, diante da intenção de permear espaços formais e não formais de educação, com a reflexão e participação social mobilizada para a defesa socioambiental através da transformação da relação com o meio ambiente. Segundo Loureiro (2006), a EA Crítica, da qual somos adeptos, possibilita a transformação das condições de vida pelo exercício da práxis alicerçada no conhecimento e na capacidade de realizar opções compromissadas com o outro e com a vida, sendo libertadora à medida em que o indivíduo se torna apto a escolher os melhores caminhos para a vida que se quer em sociedade.

Nesse sentido, a atuação baseada na EA Crítica tem potencial questionador da superprodução e superconsumo para poucos, com a busca de proteção da natureza, justiça e igualdade social, a partir da democratização do conhecimento para uma compreensão complexa e emancipatória das relações socioambientais. Para Loureiro (2006), as dimensões natural e social devem se dar não dissociadas, mas a partir contextualização social, cultural, histórica, política, ideológica e econômica, com ênfase na luta pela justiça e igualdade social. Somos adeptos deste pensamento, bem como de que, para uma consciência crítica e libertária, capaz de romper com as relações de poder, é 
necessário promover a EA Crítica, com acesso dos sujeitos a informações importantes e práticas pedagógicas que possibilitem a práxis social e a participação cidadã na construção da sustentabilidade. Nesta linha, entendemos a carência de políticas públicas de EA para a população em geral como propulsora para a imposição de práticas poluentes e a falta de garantia dos direitos sociais. Compreendemos a importância da gestão ambiental tanto a partir de regulamentação e técnicas adequadas como do incentivo, por meio de políticas públicas de EA, para a transformação do cenário socioambiental, em prol do meio ambiente saudável.

Assim, ao tratarmos sobre as possibilidades de atuação por meio da EA na política de redução da produção e da adequada destinação dos RCC, consideramos importante abordar a necessidade de que a gestão ambiental realizada pelo Estado seja democrática, com o incentivo da participação social, resultando em políticas públicas assecuratórias da cidadania7, como meio e finalidade, na consecução do meio ambiente equilibrado. As bases legais para a gestão ambiental pelo Poder Público estão no art. 225, $\$ 1^{\circ}$ da Constituição Federal (BRASIL, 1988), o qual o responsabiliza por medidas para defesa e proteção de processos ecológicos essenciais, ecossistemas, patrimônio genético, flora e fauna, sendo também sua responsabilidade a prevenção de danos e avaliação de riscos ambientais advindos de obras, criando por meio da EA condições para que a coletividade cumpra seu dever de proteger o meio ambiente.

De acordo com Quintas (2004), ao praticar gestão ambiental, o Poder Público media disputas pelo acesso e uso dos recursos ambientais, em nome do interesse público, objetivando garantir o direito ao meio ambiente ecologicamente equilibrado, conforme determina a Constituição Federal. Ainda, segundo Loureiro (2006), entendemos que a gestão ambiental e as políticas públicas de EA devem construir soluções coletivamente, através da participação dos cidadãos, ouvidos nos contextos das decisões e sendo atribuída importância ao conhecimento trazido sobre a realidade em que estão inseridos.

Neste sentido, conforme os ensinamentos de Quintas (2004), 0 desenvolvimento de capacidades (conhecimentos, habilidades e atitudes) é importante para a intervenção individual e coletiva de modo qualificado na gestão do uso dos recursos ambientais e na concepção e aplicação de

\footnotetext{
7 Consoante Oliveira e Guimarães (2004), a partir da Revolução Francesa o indivíduo passou a dispor de direitos e garantias que limitariam o poder do Estado. Nesta ocasião, a cidadania passou a ter uma dimensão além do gozo dos direitos políticos (primeira dimensão): a realização (segunda dimensão) dos direitos fundamentais de primeira dimensão acrescida do direito de participar ativamente da vida política, em decorrência dos direitos de liberdade. No século XX, a cidadania ganhou sua terceira dimensão, necessária para fruição de uma vida digna, referente ao acesso a condições fundamentais para existência, estabelecendo como fundamental para realização das outras dimensões o respeito aos direitos fundamentais, conjugando-se aquelas com direitos econômicos, sociais e culturais, e também a direitos de solidariedade e de um meio ambiente saudável. Essa posição foi reafirmada pela Declaração de Viena, de 1993. Ser cidadão, a partir desta concepção, significa ter acesso aos direitos fundamentais de primeira, segunda e terceira geração.
}

Revbea, São Paulo, V. 12, № 2: 209-228, 2017. 
decisões que afetam a qualidade do meio ambiente. Para tanto, a educação no processo de gestão ambiental deve ser realizada por profissionais habilitados, com conhecimentos e metodologias específicas, através da EA Crítica como processo educativo político gerador de consciência crítica. É preciso que a gestão ambiental praticada seja democrática, com a participação dos atores sociais envolvidos, capacitados por meio da EA para a compreensão da complexidade da problemática ambiental, incentivado o diálogo, a reflexão e a ação organizada, com criação de demandas públicas participativas, garantindo assim o controle social ${ }^{8}$. Nesta esteira, conforme Sorrentino (2010), o diálogo emancipador deverá estar presente em processos educativos capazes de conectar as pessoas, buscando compreender os atores e os conflitos sociais e assim constituindo uma autogestão que perdure após seu afastamento.

A inclusão da dimensão ambiental na educação, e a partir disso a realização de políticas públicas de EA, se consolidou com a institucionalização da Política Nacional de Educação Ambiental - PNEA (Lei 9.795/99), a qual prevê expressamente a necessidade de a EA estar presente de forma articulada em todos os níveis e modalidades do processo educativo, em caráter formal e não formal. Consoante Layrargues (2004), é instaurada uma nova ética na relação entre a sociedade brasileira e a natureza, a partir da qual as políticas públicas instituem regras do convívio social para questões emergentes ou emergenciais numa determinada coletividade, demarcando papéis sociais dos indivíduos e instituições. Fica evidenciada nesta nova ética o papel da EA como educação política, uma vez que a PNEA prevê entre os objetivos da EA o fortalecimento da cidadania e a autodeterminação dos povos, estabelecendo o incentivo à participação social na defesa da qualidade ambiental como valor inseparável do exercício da cidadania.

Vislumbramos um importante campo de atuação para a política pública ao investigarmos a possibilidade de intervenção pela EA Crítica, com vistas à participação social para a sustentabilidade, de forma emancipatória. Segundo Loureiro (2006), a EA Crítica valoriza a compreensão complexa do ambiente; a busca da realização da autonomia e liberdades humanas, redefinindo o modo como nos relacionamentos com a nossa espécie e as demais espécies e com o planeta; a atitude crítica diante da crise civilizatória, partindo do princípio de que o modo como vivemos não atende mais aos nossos anseios e que é preciso criar novos caminhos; a politização e publicização da problemática ambiental em sua complexidade; o entendimento da democracia como condição para a sustentabilidade; a convicção de que a participação social e exercício cidadania são práticas indissociáveis da EA e da democracia; a preocupação concreta em estimular o debate e o diálogo entre as ciências, redefinindo objetos de estudo e saberes; a indissociação no entendimento de processos como: produção e consumo; ética, instrumentos técnicos e contexto sociohistórico; interesses privados e interesses públicos; e a busca de ruptura e

\footnotetext{
8 "O controle social pode ser entendido como a participação do cidadão na gestão pública, na fiscalização, no monitoramento e no controle das ações da Administração Pública. Trata-se de importante mecanismo de prevenção da corrupção e de fortalecimento da cidadania" (CGU, 2012, p. 09).
}

revista brasileira educação ambiental 
transformação dos valores e práticas sociais contrários ao bem-estar público, à equidade e à solidariedade.

Conforme vimos, o cenário apresentado é de contínuo aumento da produção de RCC e crescimento de áreas degradadas, com ocorrência de descarte de resíduos nos bairros, multiplicação de vetores biológicos, desperdício de resíduo que possui valor econômico e social, com consequente necessidade de maior exploração de recursos minerais e de investimentos para realização da coleta do material. Diante disso, entendemos que há necessidade de atuação política compromissada com a EA Crítica, para que a emancipação humana confira aos cidadãos controle sobre seus destinos, construindo soluções comprometidas com a transformação social através de decisões libertadoras, que expressem genuinamente sua vontade. Compreendemos, assim, que o acesso dos riograndinos à informação sobre utilização, reuso ou destinação dos RCC é fundamental para o exercício de sua cidadania, com o incentivo à sua participação nos processos decisórios, o que deve ocorrer de forma crítica, com reflexão, construção de alternativas e posterior implementação, pelo poder público, de soluções eficazes, em defesa da sustentabilidade socioambiental.

\section{Desvelando obstáculos e construindo caminhos por meio da Educação Ambiental Crítica}

Com o intuito de investigar a potencialidade da EA na minimização da produção e na correta destinação dos RCC, foram realizadas entrevistas com gestores municipais acerca das políticas públicas e da EA realizadas no município. Para tanto, os resultados aqui apresentados foram construídos a partir do movimento recursivo, reflexivo e dialógico entre as entrevistas, as considerações teóricas e os documentos apresentados nos itens anteriores. Observamos aqui, inicialmente, que as fragilidades municipais apuradas parecem refletir um panorama geral da atual gestão dos RCC, conforme delinearemos a seguir.

O desenvolvimento de cooperativas de RCC no município é objetivo previsto no PERS-RS, com a consequente geração de trabalho e renda. A este respeito, o Secretário1 afirmou que os carroceiros que fazem coleta do RCC e descartam de forma inadequada "[...] podem ser organizados em cooperativas, eles podem funcionar de forma organizada, com espaços adequados para descarte, para separação do resíduo e agregar valor e renda para sua vida". 0 Secretário2 explica ainda que a reciclagem de materiais através das cooperativas "[...] diminui o custo que se paga pelo lixo - porque, na verdade, a gente paga hoje por peso; então a partir do momento que a gente conseguir aproveitar, reciclar isso [...], a gente deixa de pagar pelo lixo e tem renda e trabalho para as famílias". Observamos que este objetivo figura como forma de atenuar a realidade de deposição de RCC nos bairros, assim como os prejuízos dela decorrentes, atendendo ainda ao princípio expresso na PNRS, de valorização do resíduo. 
Entretanto, verifica-se que não há planejamento para a criação de uma cooperativa de RCC. Este entendimento decorre de que, perguntados sobre o estímulo para o seu funcionamento, o Secretário1 respondeu que "com o tempo o objetivo é partir da criação da central de triagem dos RCC e buscar parcerias com cooperativas e a sociedade civil para que trabalhem em esquema", o Secretário2 expôs que o incentivo "específico para os RCC eu não consigo te afirmar", enquanto o Prefeito disse que "nós vamos recuperar as cooperativas, mais especificamente de catadores", assim em momento algum referem-se a projetos em andamento específicos para cooperativas de RCC. Ou seja, os gestores identificam aspectos positivos, porém sem que haja qualquer planejamento que torne possível sua implementação, o que anuncia a necessidade de um olhar atento da gestão para o seu fomento.

Consoante afirmado pelo Secretário1, a falta de estrutura é um ponto inicial a ser trabalhado para possibilitar o incentivo às cooperativas, porquanto assim estaria viabilizada sua atuação. Observamos, assim, a importância da criação do aterro Classe $A$, como estrutura que viabiliza a atuação de cooperativas e assim as referidas consequências positivas advindas de seu funcionamento.

Outro aspecto importante para a gestão do resíduo é a existência de um banco de dados com a quantidade gerada. Conforme vimos, o levantamento de quanto resíduo é gerado em determinado período de tempo é importante, conforme o PMSB, para propostas de metas e ações eficientes e eficazes na promoção de políticas públicas de caráter preventivo, como no caso da implantação de uma usina de beneficiamento dos RCC - a qual por sua vez favoreceria o funcionamento de cooperativas.

A este respeito, o Secretário2 esclarece que o banco de dados existente é referente ao montante geral de resíduos sólidos retirado das vias "Hoje 130 toneladas de resíduos são retiradas da rua diariamente, com um recurso que a gente poderia investir em outras coisas". Neste cenário apontado por Secretário2, de destinação clandestina dos RCC, além de não se ter um quantitativo de produção, há perda de seu valor econômico e inviabilização de sua utilização posterior (PREFEITURA MUNICIPAL DO RIO GRANDE, 2013), dado que o custo para separação do material superaria o valor de venda do agregado reciclado (MMA, 2014).

Também figura como fragilidade a falta de licenciamento ambiental das empresas de coleta com consequente dificuldade de fiscalização, porquanto inexiste obrigação de que encaminhem informações sobre o quantitativo e destino final dos resíduos ao órgão ambiental (PREFEITURA MUNICIPAL DO RIO GRANDE, 2013), o que parece constituir óbice ao levantamento de dados, merecendo atenção do gestor para sua solução. Mais uma vez percebemos estar diante de realidade que aponta a necessidade de planejamento municipal, uma vez que é primordial, na gestão dos RCC, saber a quantidade gerada para o planejamento de soluções que envolvam desde cooperativas, banco de RCC, Ecopontos e o próprio aterro Classe A. 
Através das entrevistas buscamos também informações a respeito da utilização de Ecopontos para RCC, cuja criação figura como meta nacional e estadual, também prevista no PMSB, para recebimento de entulho de pequenos geradores. Entretanto, esta meta não foi implementada até 0 momento, embora existam Ecopontos para o recebimento de outros materiais (PREFEITURA MUNICIPAL DO RIO GRANDE, 2016). O Secretário1 explicou que "são ainda estruturas precárias" utilizadas para outros materiais, ao passo que o Secretário2 explicou que para RCC ainda não são utilizadas, porque que não adiantaria receber o resíduo sem uma destinação apropriada, diante da falta de estruturas no bota-fora irregular e da inexistência cooperativas aptas à destinação do material.

Assim, percebemos que ao discorrermos sobre as fragilidades municipais na gestão dos RCC, em diversos momentos aparece como obstáculo, para a implementação de outras soluções, a inexistência de aterro Classe $A^{9}$ que possua estruturas adequadas e que possibilitem recepcionar 0 material conforme sua classificação ${ }^{10}$ para preservar seu valor, o que representa assim fragilidade de central importância, dada a dependência dela para a implantação de outras soluções.

Conforme referimos, a criação do aterro Classe $A$, que possibilitaria a realização da separação do material em classes e a desativação do bota-fora irregular, figura como meta nacional e estadual, mas não como meta municipal no PMSB. Trata-se de dados publicados em 2013. Atualmente, conforme o Prefeito:

O Município do Rio Grande está em um processo de ajustamento por demanda judicial [...] já me apresentaram todo um cronograma de prazos e ações que vão culminar com a implantação dessa estrutura, desses equipamentos. Já se tem um recurso, que vai sair do Fundo Municipal de Saneamento e a ideia é que a gente possa, uma vez implantada, modificar o cenário de baixo índice de reaproveitamento de RCC.

9 Em atendimento à Resolução do CONAMA no 307/2002 (BRASIL, 2002).

10 A separação dos RCC deve ser realizada segundo sua classificação, conforme a Resolução do CONAMA no $307 / 2002$ (BRASIL, 2002).

Revbea, São Paulo, V. 12, No 2: 209-228, 2017. 
e para o fomento de cooperativas de beneficiamento de RCC, uma vez que o município passaria a contar com área capaz de recepcionar o resíduo de forma correta, com sua separação e com possibilidade de beneficiamento. Esta medida viabiliza o início de uma nova fase de gestão de RCC, respeitada a legislação que regula a matéria, em benefício do meio ambiente. Neste contexto, estamos diante de carência de estrutura e de planejamento, dois pontos a serem resolvidos pela gestão. Entretanto, não foram mencionados projetos específicos em curso para serem efetivados concomitantemente à implementação do aterro Classe A, existindo nos discursos apenas ideias, aparentemente viáveis, porém desprovidas de qualquer formalização para viabilizar sua implementação.

Observamos que as entrevistas demonstram uma postura aparentemente receptiva às mudanças necessárias à realidade desejada, o que por si só não produz efeitos sem planejamento e implementação de mudanças efetivas, parecendo-nos que as capacidades dos gestores devem ser desenvolvidas e estimuladas. Para tanto, segundo Quintas (2004), a Educação no Processo de Gestão Ambiental deve ser realizada por profissionais habilitados por meio da EA Crítica, com conhecimentos e metodologias específicas, visando 0 desenvolvimento conhecimentos, habilidades e atitudes para a elaboração de soluções que afetam a qualidade do meio ambiente. Entendemos que há necessidade de investir de forma continuada neste desenvolvimento de capacidades para que as soluções sejam elaboradas. A preparação específica dos gestores através da EA Crítica, apesar de não estar expressamente prevista nas políticas e planos pesquisados, facilitaria o alcance de um dos princípios da PNRS, que é a visão sistêmica, na gestão dos resíduos sólidos, que considere as variáveis ambiental, social, cultural, econômica, tecnológica e de saúde pública.

Ainda, conforme vimos através dos ensinamentos de Quintas (2004), é de suma importância a participação popular em esferas de decisão, a fim de que se tenha uma gestão democrática e assim o estímulo ao exercício da cidadania, a qual, segundo Oliveira \& Guimarães (2004), se dá com a efetiva participação do cidadão na tomada de decisões individuais e coletivas. Entende-se que a EA reforçará o entendimento do gestor sobre a necessidade de sua promoção também para sociedade civil em geral, a fim de que esta participe buscando a superação de problemas socioambientais e não apenas de demandas individuais.

Nesse sentido, lembramos ainda que a participação social para a autogestão está expressamente elencada como princípio do PMSB, conforme expusemos, devendo ser promovida através do protagonismo social. Conforme explica Quintas (2004), para a gestão democrática é preciso a participação dos atores sociais envolvidos, valorizado o diálogo para a implementação de políticas públicas que funcionem, uma vez que constituídas não unilateralmente pelos gestores, mas junto a cidadãos preparados para realizar autogestão através de uma educação política. Observamos que, consoante Sorrentino (2010), uma política pública que promova um diálogo emancipador em espaços

revista brasileira educação ambiental 
formais e não formais de aprendizagem, a partir de profissionais qualificados para impulsionar o envolvimento e o compromisso de todos, é capaz de constituir uma autogestão que perdure após seu afastamento.

Desse modo, por meio de uma atuação alicerçada na problematização consciente e libertadora que, conforme Loureiro (2006), caracteriza a EA Crítica, de gestores e da sociedade civil continuamente capacitados, entendemos que é possível a médio prazo a realização de uma gestão democrática.

Uma vez demonstrada essencial, segundo os ensinamentos de Quintas (2004), a atuação da gestão mediante profissionais habilitados que intervenham através da EA Crítica, tanto na elaboração de soluções sustentáveis, como na promoção da participação capacitada da sociedade civil nos processos decisórios, passamos à análise da forma como a EA é compreendida pela gestão municipal.

Buscamos então junto aos gestores seu entendimento do que é EA e de qual forma ela poderia ser trabalhada para auxiliar na problemática dos RCC. Segundo o Prefeito, a EA deve ser trabalhada na sala de aula, com intuito de mudar culturas através dos jovens, enquanto o Secretário2 esclarece que a EA é realizada atualmente nas escolas, "[...] plantando sementinhas para colher futuramente". Assim, percebemos forte impregnação da EA de cunho conservador ${ }^{11}$, o que é preocupante quando defendemos a necessidade de participação popular e de políticas públicas de EA Crítica.

Como vimos, o PNRS (MMA, 2012) prevê ações de EA para mobilizar o interesse e a participação da sociedade civil, salientando que as atividades não devem estar restritas ao ambiente escolar, o que deixaria de considerar a população como um todo. Também Sorrentino (2010) salienta a necessidade de superação da ideia de que a EA deve ser realizada apenas com crianças nas escolas, sob a justificativa de que os adultos serão educados através delas. Assim, o entendimento de EA trazido pelos entrevistados até o momento se revela demasiadamente limitado.

Para o Secretário1, o conceito de EA é mais amplo e deve alcançar além dos espaços formais de educação, deve romper o paradigma tradicional de abordagem escolar, para integrar o cotidiano das pessoas, sendo levada até elas nos mais diversos ambientes, de modo que todos sejam atingidos de alguma forma. É a partir de sua fala que visualizamos a perspectiva de atuação da gestão municipal comprometida com a EA Crítica para a população como um todo:

11 Conforme Layrargues e Lima (2011), a vertente conservadora tem enfoque para práticas educativas com crianças na escola e em mudanças de hábitos no âmbito doméstico.

Revbea, São Paulo, V. 12, № 2: 209-228, 2017. 
[...] nós temos que ver a política de Educação Ambiental muito além daquela coisa do animalzinho, do gatinho, do cachorrinho, do passarinho etc., ou do separa-se o lixo, ou da Educação Ambiental infantil. Não. A Educação Ambiental tem que ser tratada como um elemento institucional, ela tem que estar incorporada no dia a dia da administração, e tem que ser uma política de Estado.

Desse modo, além de EA para o gestor, fica clara a necessidade de EA para a população em geral, tanto para o cuidado com o meio ambiente quanto para a participação na elaboração e a compreensão das medidas adotadas na solução dos problemas socioambientais. Nesse sentido, Layrargues e Lima (2011) ensinam que para que os cidadãos tomem decisões libertadoras, que expressem genuinamente sua vontade, é necessária uma ação coletiva, sinérgica, atuante na contradição existente entre a EA Crítica e a articulação com projetos societários que servem a interesses particulares. Ainda, se configura a necessidade de evolução da EA trabalhada no município, para que seja pautada na teoria crítica, deixando de ter seu foco principal restrito às escolas para permear também a gestão e os diversos grupos sociais, de modo contínuo e duradouro. Esta evolução pressupõe o envolvimento da gestão na construção de soluções junto com a população, comprometidas com a transformação social.

Compreendemos, através do estudo das fragilidades municipais, que a gestão dos RCC tem sido relegada a segundo plano, com prejuízo socioambiental de relevante proporção. Entendemos também que, para que o gestor desenvolva um olhar atento para a problemática, deve contar com capacitação, através de cursos oferecidos por profissionais qualificados. Ainda, para uma autogestão democrática que perdure com a troca de seus representantes eleitos, devem ser implementadas políticas públicas de EA também para os diversos grupos sociais, incentivando o exercício das responsabilidades individuais e coletivas, para uma gestão participativa, que represente ideais conjuntos, com incentivo à práxis e assim ao exercício da cidadania.

Diante do exposto, observamos que para a atuação eficaz dos gestores frente à problemática dos RCC no Município do Rio Grande é importante um diálogo crítico, direcionado à construção de um projeto de futuro, alicerçado sobre ideais conjuntos, ao mesmo tempo em que este diálogo permita compreender a sociedade de forma a sentir-se potente para transformá-la, com a superação de interesses imediatistas e o desenvolvimento de um compromisso com a vida.

Assim, compreendemos que a gestão ambiental a ser realizada deve contar com profissionais capacitados por meio da EA Crítica para uma gestão democrática e participativa, garantindo a expressão dos diferentes grupos sociais na adoção de medidas. A gestão ambiental democrática pressupõe a participação dos atores sociais envolvidos, capacitados por meio da EA para o

revista brasileira educação ambiental 
exercício do controle social ${ }^{12}$, com consequente fortalecimento da cidadania (QUINTAS, 2004). Esta participação deve ser levada a efeito através da recepção de representantes dos diversos segmentos sociais nos espaços de decisão, havendo comprometimento do gestor com a explicitação e mediação dos conflitos de interesses das classes locais. As políticas públicas deverão incentivar o exercício das responsabilidades individuais e coletivas, prevendo a EA Crítica também para os diversos grupos sociais, com incentivo à práxis e assim ao exercício da cidadania.

$\mathrm{Da}$ análise das fragilidades estruturais e da falta de EA Crítica expostos supra, salientamos a necessidade de a gestão valorizar as oportunidades de discussão entre gestores e sociedade, para que a administração dos RCC no município seja regida por interesses coletivos, valorizado o conhecimento dos diversos grupos sociais e o exercício da cidadania na construção de soluções, sempre objetivando a participação popular e a educação na consecução do bem comum.

\section{Considerações}

Com o advento da PNRS, anunciou-se uma nova fase de gestão de RCC, em benefício do meio ambiente. Entretanto, verificada em grande parte a adequação da regulamentação municipal aos preceitos legais, foram detectadas ainda algumas fragilidades. Ademais, o diagnóstico de coleta e destinação de resíduos apresenta irregularidades importantes, como a perda de valor do material, a degradação ambiental e consequências socioambientais relevantes advindas da contaminação ambiental, sem que práticas de EA Crítica sejam fomentadas pela gestão para auxiliar na construção de soluções coletivamente.

Entendida a EA como educação política, há necessidade que a gestão priorize o acesso da informação aos cidadãos, viabilizando melhor atuação dos indivíduos e dos grupos, a fim de que estejam preparados para exigir cidadania nacional e planetária, autogestão e ética nas relações sociais e com a natureza. A participação social na resolução dos problemas socioambientais pressupõe conhecimento e consciência da problemática ambiental, que podem ser incentivados através da EA Crítica.

Assim, a gestão de RCC no Município do Rio Grande, assim como a EA Crítica, apresentam-se como importantes instrumentos políticos para ajudar a sociedade a refletir sobre as suas práticas e transformar sua atuação, com o despertar de uma compreensão crítica e motivadora com repercussão socioambiental através da práxis consciente, considerados os interesses transindividuais e para além do desenvolvimento econômico. Neste sentido, é necessária uma política de motivação e sensibilização para minimizar a produção e maximizar a reciclagem/reutilização dos RCC, tanto para os geradores de RCC como para a sociedade civil.

12 Lembrando que o controle social é princípio previsto na PNRS (BRASIL, 2010).

Revbea, São Paulo, V. 12, No 2: 209-228, 2017. 
Observamos que as ações de EA descritas no PMSB estão desvestidas de análise crítica, da reflexão, da consciência e da práxis social, sendo incapazes deste modo de atingir o caráter emancipatório desejado, revelada assim a necessidade de atuação da administração pública, para realização de atividades de EA Crítica.

A partir do diálogo entre os documentos e argumentos teóricos e as entrevistas realizadas, foram revelados aspectos importantes para a criação de soluções, por meio da EA Crítica, para a temática dos RCC. Observamos que, para a atuação eficaz dos gestores, é preciso que sejam capacitados a partir da EA Crítica, com o conhecimento de práticas sustentáveis e aptidão para a realização de uma gestão participativa, valorizado o conhecimento dos grupos sociais, as necessidades das minorias e os interesses transindividuais. Constatamos também a necessidade de que a problemática dos RCC, hoje preterida, seja elevada a primeiro plano, com vistas à sustentabilidade socioambiental e à construção participativa de um projeto de futuro, que represente ideais conjuntos, com consequente fortalecimento da cidadania e da autogestão.

Desse modo, entendemos que a reunião de gestores e sociedade capacitados pela EA Crítica, agindo contínua, participativa e democraticamente em prol da sustentabilidade, consideradas as relações socioambientais como um todo, apresenta potencial transformador para a realidade da produção e da adequada destinação dos RCC no Município do Rio Grande - RS.

\section{Referências}

ABRELPE - ASSOCIAÇÃO BRASILEIRA DE LIMPEZA PÚBLICA E RESÍDUOS ESPECIAIS. Panorama dos resíduos sólidos no Brasil 2015. Abrelpe, 2015.

ANDRÉ, M.E.D A. Estudo de caso em pesquisa e avaliação educacional. Brasília: Liber Livro Editora, 3ª edição, 2008.

BRASIL. Constituição (1988). Constituição da República Federativa do Brasil. Brasília, DF: Senado, 1988.

BRASIL. LEI no 9.605, de 12 de fevereiro de 1998. Dispõe sobre sanções penais e administrativas derivadas de condutas e atividades lesivas ao meio ambiente. Diário Oficial da República Federativa do Brasil, Brasília, 13 fev 1998.

BRASIL. LEI № 9.795, de 27 de abril de 1999. Dispõe sobre a educação ambiental, institui a Política Nacional de Educação Ambiental; Diário Oficial da República Federativa do Brasil, Brasília, 28 de abril de 1999.

BRASIL. LEI № $\mathbf{8 . 0 7 8}$, de 11 de setembro de 1990. Dispõe sobre a proteção do consumidor e dá outras providências; Diário Oficial da República Federativa do Brasil, Brasília, 10 jan 2007. 
BRASIL. LEI no 12.305, de 02 de agosto de 2010. Institui a Política Nacional de Resíduos Sólidos. Diário Oficial da República Federativa do Brasil, Brasília, 03 ago 2010.

BRASIL. Ministério do Meio Ambiente. Resolução CONAMA no 307 , de 5 de julho de 2002. Estabelece diretrizes, critérios e procedimentos para a gestão dos RCC; Diário Oficial da República Federativa do Brasil, Brasília, 17 jul 2002.

BRASIL. Ministério do Meio Ambiente. Diretoria de Educação Ambiental; Philippe Pomier Layrargues (coord.). Identidades da educação ambiental brasileira. Brasília: MMA, 2004.

BRASIL. Ministério das Cidades. Ministério do Meio Ambiente. Áreas de manejo de resíduos da construção e resíduos volumosos. 2005.

BRASIL. Plano Nacional de Resíduos Sólidos. Brasília: Agosto de 2012.

CAPORLINGUA, V.H. A Consciência Ambiental dos Juízes nas Sentenças Transformadoras. Jundiaí: Paco Editorial, 2012.

CONTROLADORIA GERAL DA UNIÃO. Controle Social: orientação para participação na gestão pública e exercício do controle social. Brasília: 2012.

FORUM INTERNACIONAL DAS ONGs. Tratado de educação ambiental para sociedades sustentáveis e responsabilidade global. Rio de Janeiro: 1992.

KARPINSK, L.A. Gestão Diferenciada dos Resíduos da Construção Civil: uma abordagem ambiental. Porto Alegre: Edipucrs, 2009.

LAYRARGUES, P.P.; LIMA, G.F.C. Mapeando as macrotendências políticopedagógicas da educação ambiental contemporânea no Brasil. Anais do VI Encontro Pesquisa em Educação Ambiental, Ribeirão Preto: USP, 2011. p.1-15.

LOUREIRO, C.F.B. Sustentabilidade e Educação: um olhar da ecologia política. Coleção questões da nossa época. São Paulo: Cortez, 2012. v. 39.

LOUREIRO, C.F.B. Trajetória e fundamentos da educação ambiental. São Paulo: Cortez, 2006.

GOVERNO DO ESTADO DO RIO GRANDE DO SUL. PERS - RS Plano Estadual de Resíduos Sólidos do Rio Grande do Sul (2015-2034), 2014.

MORAES, R.; GALIAZZI, M.C. Análise textual discursiva. ljuí: Ed. Unijuí, 2007.

PREFEITURA MUNICIPAL DO RIO GRANDE. Concepção dos Programas, Diagnóstico, Prognóstico e Proposição de Alternativas para o Sistema de Saneamento. Relatório de Caracterização Municipal. Rio Grande, 2013.

QUINTAS, J.S. Educação no processo de gestão ambiental: uma proposta de educação ambiental transformadora e emancipatória. In: LAYRARGUES, P.P. (org.). Identidades da Educação Brasileira. Brasília: MMA, p.113-140. 2004.

SORRENTINO, M.; NASCIMENTO, E.P. Universidade e Políticas Públicas de Educação Ambiental. Educação em Foco (Juiz de Fora), v. 14, p. 15-38, 2010.

Revbea, São Paulo, V. 12, № 2: 209-228, 2017. 